\title{
Endocuff-assisted versus Cap-assisted Colonoscopy in Increasing Adenoma Detection Rate: a Meta-Analysis
}

\author{
Antonio Facciorusso, Rosario Vincenzo Buccino, Rodolfo Sacco
}

Gastroenterology Unit,

Department of Medical

Sciences, University of Foggia,

Foggia, Italy

\author{
Address for correspondence: \\ Antonio Facciorusso \\ Division of Gastroenterology \\ University of Foggia \\ Viale Luigi Pinto, 1 \\ Foggia, 71100, Italy \\ antonio.facciorusso@virgilio.it
}

Received: 17.03.2020

Accepted: 20.05 .2020

\begin{abstract}
Background \& Aims: Several add-on devices have been developed to increase rates of colon adenoma detection. We aimed to compare the endocuff-assisted colonoscopy with cap-assisted colonoscopy through a pairwise meta-analysis of randomized trials.

Methods: We searched the PubMed/Medline and Embase database through March 2020 and identified 6 randomized controlled trials (comprising 2,027 patients). The primary outcome was adenoma detection rate; secondary outcomes included sessile serrated adenoma detection rate, mean adenoma per colonoscopy, cecal intubation rate and time to reach cecum. Safety data were also analyzed. We performed pairwise meta-analysis through a random effects model and expressed data as risk ratio and $95 \%$ confidence interval.

Results: Overall, pooled adenoma detection rate was $48.1 \%$ (39.3-56.8\%) with endocuff and 40.5\% (30.4$50.6 \%$; risk ratio $1.14,0.96-1.35)$ with cap. Proximal adenoma detection rate was $45.7 \%$ (36.8-54.7\%) and $24 \%$ (17-45.1\%) with endocuff and cap, respectively (risk ratio 2.04, 0.93-4.49), whereas endocuff outperformed cap-assisted colonoscopy in detecting diminutive ( $\leq 5 \mathrm{~mm}$ ) adenomas (risk ratio 2.74, 1.53-4.90) and in terms of mean adenoma per colonoscopy (mean difference $0.31,0.05-0.57 ; \mathrm{p}=0.02$ ). Sessile serrated adenoma detection rate (risk ratio $1.36,0.72-2.59$ ), cecal intubation rate (risk ratio $0.99,0.98-1.00$ ), and time to reach cecum (6.87 min versus $6.87 \mathrm{~min}$ ) were similar between the two groups. No serious adverse event was observed. Conclusion: Endocuff-assisted colonoscopy seems to provide a higher adenoma detection rate as compared to cap-assisted colonoscopy, in particular concerning smaller diminutive polyps.
\end{abstract}

Key words: cap - endocuff - colonoscopy - adenoma detection rate

Abbreviations: ADR: adenoma detection rate; aADR: advanced ADR; AMR: adenoma miss rate; CRC: colorectal cancer; HD: high-definition; FUSE: full-spectrum endoscopy; RCT: randomized-controlled trial; SSADR: sessile serrated ADR.

\section{INTRODUCTION}

Colorectal cancer (CRC) is the third most common cancer and the third leading cause of cancerrelated mortality worldwide [1]. In order to interrupt the adenoma-carcinoma sequence [2], screening and surveillance programs were implemented in several countries and early detection of colon polyps associated with effective polypectomy were found to have a significant impact on patient survival [3].
Adenoma detection rate (ADR), defined as the percentage of colonoscopies with at least one adenoma identified, has been recognized as a key performance measure for quality colonoscopy $[4,5]$, with a reported inverse correlation with risk of interval CRC (quantified as each 1.0\% increase in ADR being associated with $3 \%$ decrease in risk of interval CRC) and mortality [6].

Unfortunately, ADR varies widely ranging from 5 to $37.5 \%$ [4] depending on both adjunctive factors, such as improvement in bowel preparation [7] and implementation of minimal withdrawal time [8], and technological innovations. A recent network meta-analysis published by our group showed that add-on devices, enhanced imaging techniques and low-cost optimization of existing resources (particularly water-aided colonoscopy) are associated with significant improvement in ADR and advanced ADR (aADR), whereas a clear benefit of 
newer costly scopes over high-definition (HD)-colonoscopy was not observed [9]. Considering individual devices, while full-spectrum endoscopy (FUSE) showed discording results $[10,11]$, endoscopic add-on devices aimed at improving visualization behind folds were proved to be effective both in terms of ADR and adenoma miss rate (AMR) based on tandem randomized-controlled trials (RCTs) $[12,13]$. In particular, our group has recently demonstrated the improvement in ADRs with use of distal attachment devices, particularly with endocuff (Endocuff , Arc Medical Design, Leeds, UK) and in low-performing endoscopists, without clear benefit of one device over another [12]. However, one of the main limitations of the aforementioned meta-analysis [12] was the very limited number of head-to-head trials directly comparing the different devices which prevented reaching definitive conclusions on their comparative effectiveness.

In recent years a number of RCTs comparing the two most frequently used add-on devices, namely endocuff and cap (Olympus Medical Systems, Tokyo, Japan), have been published; therefore, we decided to perform a pairwise metaanalysis comparing the relative efficacy of these add-on devices for the improvement of colon ADR.

\section{METHODS}

\section{Selection criteria}

Studies included in this meta-analysis were RCTs published either in full-text or as congress abstracts, that met the following inclusion criteria: (a) patients: adults undergoing elective colonoscopy; (b) intervention: endocuff-assisted colonoscopy (c) comparator: cap-assisted colonoscopy; and (d) outcome: ADR as primary outcome, mean adenoma per colonoscopy, sessile serrated adenoma detection rate (SSADR), cecal intubation rate and cecal intubation time as secondary outcomes. Safety data were also analyzed.

We excluded (a) observational studies, (b) trials comparing endocuff or cap versus standard colonoscopy.

\section{Search strategy}

Supplementary Table I reports the search strategy followed in the meta-analysis.

A computerized bibliographic search was performed on PubMed/Medline and Embase with no language restriction, independently by two authors (A.F. and R.V.B.) using the following text words and corresponding Medical Subject Heading/Emtree terms: "colonoscopy", "endoscopy", "adenoma", "polyp", “cap", "hood”, "endocuff” through March 2020. A complementary manual search was performed on additional databases (Google Scholar, Cochrane library) and by checking the references of all the main review articles on this topic, in order to identify possible additional studies. In cases of repetitive publications from the same population, only the most recent and complete articles were included.

The quality of the included studies was assessed by two authors independently (A.F. and R.V.B.) according to the Cochrane Collaboration's tool for assessing the risk of bias [14]. Any disagreements were addressed by re-evaluation and following a third opinion (R.S.).

\section{Statistical analysis}

Study outcomes were pooled and compared between the two groups through a random-effects model based on the DerSimonian and Laird test, and results were expressed in terms of risk ratio (RR) and 95\% confidence interval (CI).

Presence of heterogeneity was calculated through $\mathrm{I}^{2}$ tests with $\mathrm{I}^{2}<20 \%$ interpreted as low-level heterogeneity and $\mathrm{I}^{2}$ between 20 and $50 \%$ as moderate heterogeneity. Any potential publication bias was verified through the visual assessment of funnel plots.

Subgroup analysis in the context of the primary outcome was restricted a) right-sided adenomas and b) diminutive $(<5$ $\mathrm{mm}$ ) adenomas. Sensitivity analysis was restricted a) high quality studies, b) newer endocuff device (Endocuff Vision ${ }^{\oplus}$, Arc Medical Design, Leeds, UK).

Safety outcomes were inconsistently reported and analyzed descriptively.

All statistical analyses were conducted using RevMan version 5 from the Cochrane collaboration. For all calculations a two-tailed $p$ value of less than 0.05 was considered statistically significant.

\section{RESULTS}

\section{Included studies}

From 2,754 unique studies identified using the search strategy, we included 6 RCTs [16-21] (Fig. 1) recruiting 2,027 patients, of whom 1,014 were undergoing endocuff-assisted colonoscopy and 1,013 cap-assisted colonoscopy.

The main baseline characteristics of the included studies are summarized in Table I.

The recruitment period ranged from 2015 to 2019 and one RCT was conducted in Japan [16] whereas 5 studies were conducted in Western countries [17-21]. Three studies $[17,18,20]$ were 3 -arm trials comparing endocuff versus cap versus standard colonoscopy, of which only the first two arms were included in the meta-analysis, and two studies were published as conference abstracts $[17,20]$. The trial by Rameshshanker et al. [19] was a back-to-back tandem study where each patient underwent two procedures in the same day and only data from the first colonoscopy were considered in this meta-analysis.

Two studies $[19,21]$ tested the new Endocuff Vision ${ }^{\circledR}$ and all the procedures were performed by experienced endoscopists, except for the trial by Imaeda et al. [16] where nearly half of the colonoscopies were performed by trainees.

Baseline patient- and polyp-related characteristics were well-balanced between the two study groups, with males forming the majority of participants in the included studies while most detected polyps were under $5 \mathrm{~mm}$. All the studies used high-definition scopes.

Overall and study-level quality assessments are summarized in Supplementary Figs. 1A and B, respectively. Overall, the studies were felt to be at moderate risk of bias, mainly due to performance and detection bias related to the unblinded design of the included RCTs. Two abstracts $[17,20]$ were considered a higher risk of bias due to incomplete outcome reporting. 


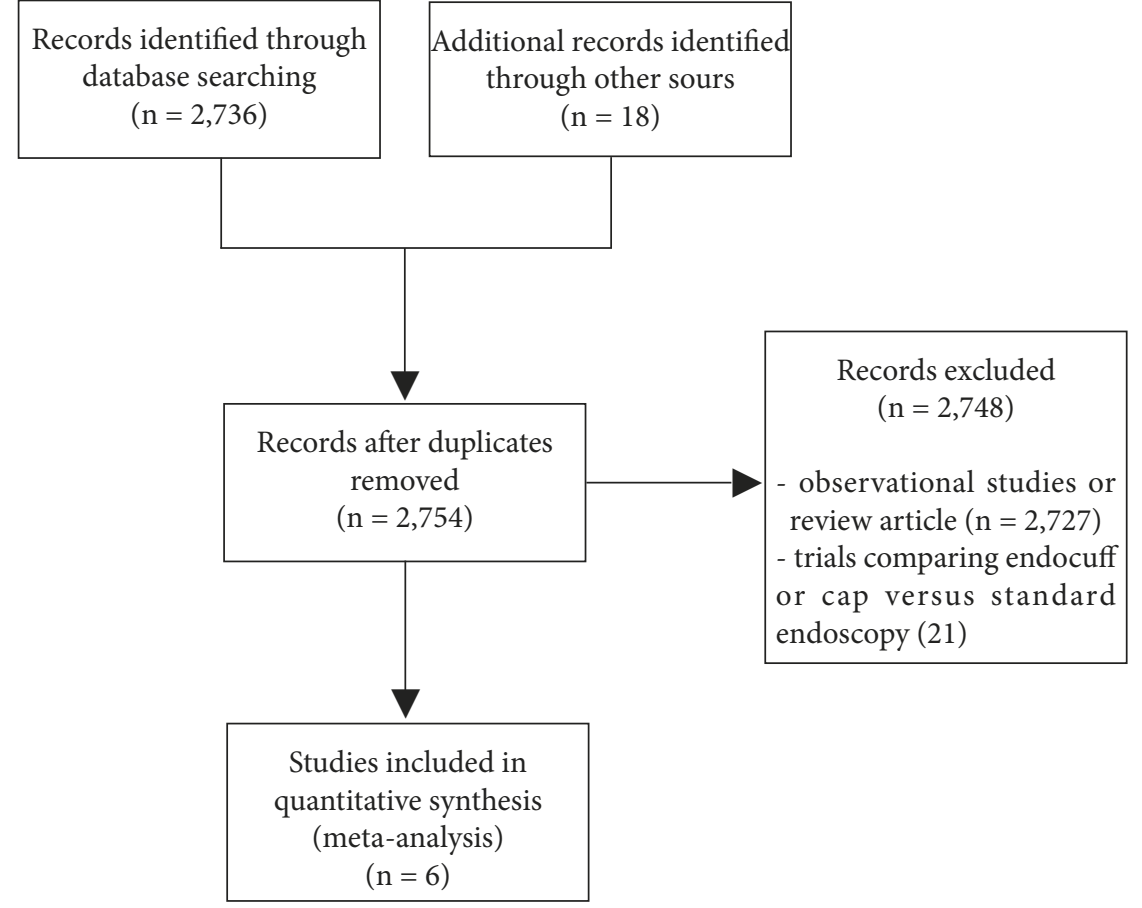

Fig. 1. Study selection flow chart.

\section{Adenoma detection rate}

Overall, based on 6 RCTs [16-21] (2,027 patients), the pooled ADR was $48.1 \%$ (95\% CI 39.3-56.8\%) with endocuff and $40.5 \%$ (30.4-50.6\%) with cap and no significant difference was observed between the two add-on devices (RR 1.14, 95\% CI 0.96-1.35; Fig. 2). Moderate evidence of heterogeneity was observed $\left(\mathrm{I}^{2}=41 \%\right)$ mainly due to a single outlier study [19]; in fact, leave-one-out sensitivity analysis based on exclusion of the single aforementioned trial [19] led to a significant decrease in heterogeneity to $19 \%$. No evidence of publication bias was found (Supplementary Fig. 2).

Other sensitivity analyses restricted to high-quality studies $[16,18,19,21]$ and to RCTs using Endocuff Vision ${ }^{\bullet}[19,21]$ confirmed the findings of the main analysis, although the high

Table I. Characteristics of included randomized controlled trials comparing Endocuff-assisted and Cap-assisted colonoscopy

\begin{tabular}{|c|c|c|c|c|c|c|c|c|c|}
\hline Study, Year & $\begin{array}{l}\text { Location; } \\
\text { Recruitment } \\
\text { period; } \\
\text { Design }\end{array}$ & $\begin{array}{l}\text { Interventions } \\
(\mathrm{N})\end{array}$ & Age years & $\begin{array}{l}\text { Gender } \\
\text { male }\end{array}$ & $\begin{array}{l}\text { Indications } \\
\text { Screening }\end{array}$ & $\begin{array}{l}\text { Trainee } \\
\text { involvment }\end{array}$ & $\begin{array}{l}\text { Bowel } \\
\text { preparation } \\
\text { (Excellent/ } \\
\text { Good) }\end{array}$ & $\begin{array}{l}\text { Right- } \\
\text { sided } \\
\text { polyps }\end{array}$ & $\begin{array}{l}\text { Size }(\leq 5 \mathrm{~mm} / \\
-9 \mathrm{~mm} / \\
\geq 10 \mathrm{~mm})\end{array}$ \\
\hline $\begin{array}{l}\text { Imaeda, } 2017 \\
{[16]}\end{array}$ & $\begin{array}{l}\text { Japan; 2015- } \\
\text { 2016; Parallel }\end{array}$ & $\begin{array}{l}\text { Endocuff (250) } \\
\text { Transparent } \\
\text { Hood (258) }\end{array}$ & $\begin{array}{l}64.5(31-92) \\
3.9(28-85)\end{array}$ & $\begin{array}{l}151(60.4 \%) \\
165(63.9 \%)\end{array}$ & $\begin{array}{l}115(46 \%) \\
127(49.2 \%)\end{array}$ & $\begin{array}{l}2(50 \%) \\
\text { operators }\end{array}$ & $\begin{array}{l}250(100 \%) \\
258(100 \%)\end{array}$ & $\begin{array}{l}74(22.9 \%) \\
80(25.8 \%)\end{array}$ & $\begin{array}{l}64.8 \% / 18.3 \% \\
/ 16.9 \% \\
55.2 \% / 20.3 \% \\
/ 24.5 \%\end{array}$ \\
\hline Floer, $2018\left[^{17]^{\mathrm{a}}}\right.$ & $\begin{array}{l}\text { Germany- } \\
\text { Poland; 2015- } \\
\text { 2019; 3-arm } \\
\text { Parallel }^{\star}\end{array}$ & $\begin{array}{l}\text { Endocuff (189) } \\
\text { Cap (189) }\end{array}$ & NR & NR & NR & No & NR & NR & NR \\
\hline $\begin{array}{l}\text { Marsano, } 2019 \\
{[18]}\end{array}$ & $\begin{array}{l}\text { USA; 2016- } \\
\text { 2017; 3-arm } \\
\text { Parallel }^{*}\end{array}$ & $\begin{array}{l}\text { Endocuff (42) } \\
\text { Cap (42) }\end{array}$ & $\begin{array}{l}60 \pm 6.8 \\
60 \pm 6.7\end{array}$ & $\begin{array}{l}23(54.8 \%) \\
24(57.1 \%)\end{array}$ & $\begin{array}{l}33(78.5 \%) \\
32(76.2 \%)\end{array}$ & No & $\begin{array}{l}8.9 \pm 0.3+ \\
8.9 \pm 0.5\end{array}$ & $\begin{array}{l}50 \%{ }^{\circ} \\
35.7 \%\end{array}$ & NR \\
\hline $\begin{array}{l}\text { Rameshshanker, } \\
2020 \text { [19] }\end{array}$ & $\begin{array}{l}\text { UK; 2016- } \\
\text { 2017; Tandem }\end{array}$ & $\begin{array}{l}\text { Endocuff } \\
\text { Vision (76) } \\
\text { Cap (78) }\end{array}$ & $\begin{array}{l}61.9 \pm 14.7 \\
60.8 \pm 12.6\end{array}$ & $\begin{array}{l}36(47.4 \%) \\
43(55.1 \%)\end{array}$ & No & No & $\begin{array}{l}76(100 \%) \\
78(100 \%)\end{array}$ & $\begin{array}{l}43.3 \%^{\circ} \\
14.2 \%^{\circ}\end{array}$ & $\begin{array}{l}42.1 \% / 22.4 \% \\
/ 17.1 \%^{\circ} \\
15.4 \% / 16.7 \% \\
/ 3.9 \%^{\circ}\end{array}$ \\
\hline $\begin{array}{l}\text { Sanchez Yague, } \\
2019\left[^{20]^{\mathrm{a}}}\right.\end{array}$ & $\begin{array}{l}\text { Spain; 2016- } \\
\text { 2017; 3-arm } \\
\text { Parallel }\end{array}$ & $\begin{array}{l}\text { Endocuff (100) } \\
\text { Cap (92) }\end{array}$ & 57.17 & NR & NR & NR & $7.65+$ & NR & NR \\
\hline $\begin{array}{l}\text { Sola-Vera, } 2019 \\
\text { [21] }\end{array}$ & $\begin{array}{l}\text { Spain; 2017; } \\
\text { Parallel }\end{array}$ & $\begin{array}{l}\text { Endocuff } \\
\text { Vision (357) } \\
\text { Cap (354) }\end{array}$ & $\begin{array}{l}65(19-92) \\
64(18-92)\end{array}$ & $\begin{array}{l}188(52.7 \%) \\
175(49.4 \%)\end{array}$ & $\begin{array}{l}92(25.8 \%) \\
87(24.6 \%)\end{array}$ & No & $\begin{array}{l}310(89.1 \%) \\
297(87.6 \%)\end{array}$ & $\begin{array}{l}43.7 \% \\
43.7 \%\end{array}$ & $\begin{array}{l}70.3 \% / 16.4 \% \\
/ 13.3 \% \\
65.3 \% / 17.6 \% \\
/ 17.1 \%\end{array}$ \\
\hline
\end{tabular}

${ }^{a}$ Data reported as congress abstracts. ${ }^{*}$ Only Endocuff and Cap arms were included in the analysis. +Data reported as Boston bowel preparation scale.

${ }^{\circ}$ Data reported as adenoma detection rate. Abbreviations: NR-Not reported 


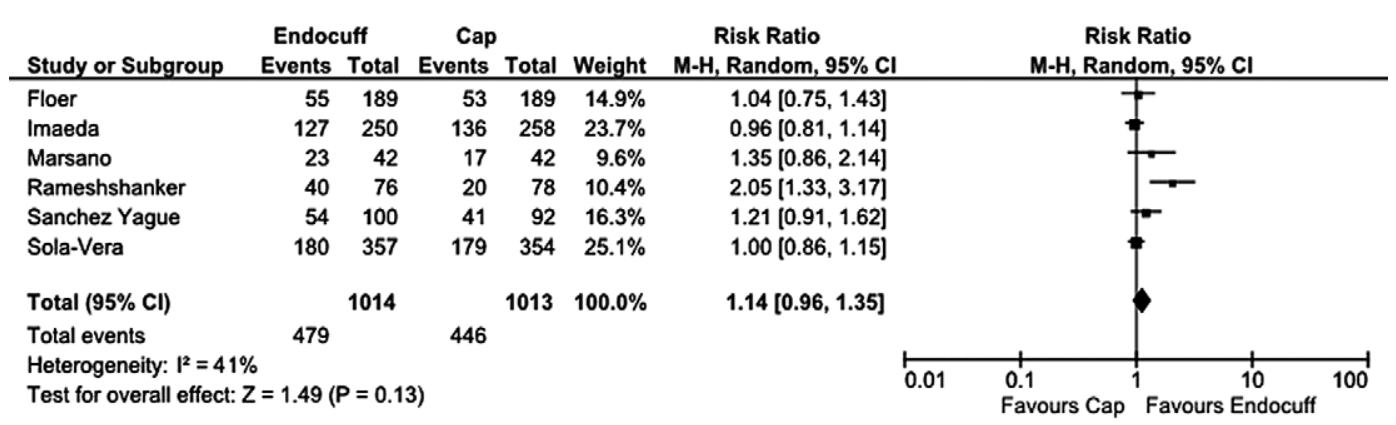

Fig. 2. Forrest Plot comparing endocuff-assisted and cap-assisted colonoscopy for the adenoma detection rate Pooled adenoma detection rate was $48.1 \%$ (95\% confidence interval 39.3\%-56.8\%) with endocuff and 40.5\% (30.4\%-50.6\%) with cap. No significant difference between the two methods was observed, with a risk ratio of 1.14 (95\% confidence interval 0.96-1.35)

heterogeneity found in the subset of studies using Endocuff Vision ${ }^{\circledast}$ requires particular caution in the interpretation of these results (Table II).

Proximal ADR (i.e. ADR restricted to right-sided polyps) was $45.7 \%(36.8-54.7 \%)$ and $24 \%(17-45.1 \%)$ with endocuff and cap, respectively (RR 2.04, 0.93-4.49; Table II), whereas endocuff outperformed cap-assisted colonoscopy in the sub-analysis which focused on diminutive $(\leq 5 \mathrm{~mm})$ adenomas (pooled ADR 44.9\%, 35.9-53.8\% with endocuff and $24.6 \%, 17.4-44.5 \%$ with cap; RR 2.74, 1.53-4.90; Table II). Heterogeneity in subgroup analyses was low to moderate.

\section{Secondary outcomes}

Based on 5 RCTs [16-19, 21] (1,835 patients), endocuffassisted colonoscopy significantly increased mean adenoma per colonoscopy as compared to cap (mean difference 0.31 , 0.05 to $0.57 ; \mathrm{p}=0.02$; Fig. 3 ), with moderate heterogeneity $\left(\mathrm{I}^{2}=41 \%\right)$.

The other secondary outcomes are reported in Table III.

Three RCTs $[16,18,19]$ enrolling 746 patients did not report a significant difference in terms of increased SSADR with endocuff in comparison to cap $(9.6 \%, 0-19 \%$ versus $6.8 \%$, $0-15 \%$; RR 1.36, 0.72-2.59; $\mathrm{I}^{2}=0 \%$ ).

Cecal intubation rate was similar between the two groups (RR 0.99, 0.98-1.00; $\mathrm{I}^{2}=19 \%$ ), based on 5 RCTs [16, 18-21]. Time to reach cecum was also similar between endocuffassisted and cap-assisted colonoscopy (6.87 $\mathrm{min}, 3.95-9.78$ and $6.87 \mathrm{~min}, 3.91-9.83$; respectively) based on 4 RCTs [16, $18,19,21]$ (1457 patients)
Adverse events were inconsistently reported, and hence, are described qualitatively in Supplementary Table II. No serious adverse event was observed.

\section{DISCUSSION}

Recent interest has been raised on the development of novel techniques and devices aimed to improve ADR. Among them, simple add-on devices that can be attached to the tip of the endoscope evidenced interesting results in terms of increased ADR by flattening colonic folds and enabling a direct view behind them $[9,12,13]$.

Current guidelines $[4,22]$ recognize the interesting role of these devices for improving ADR, confirmed in several recent meta-analyses $[9,12,13,23,24]$, but state that definitive assumptions on their superiority over standard colonoscopy or each other cannot be made due to limited comparative data. In particular, there is no direct evidence on the comparison between the two most common add-on devices, namely endocuff and cap.

Through a pairwise meta-analysis, to the best of our knowledge the first systematic review on the comparison between endocuff and cap, we made several key observations. First, no significant difference was observed in terms of ADR between the two devices (pooled ADR 48.1\% versus $40.5 \%$ ). This finding was confirmed also in the subset of right-sided polyps (usually the lesions more difficult to detect due to their flat morphology) and considering the newer endocuff device (Endocuff Vision $\left.{ }^{\circledast}\right)$. Second, the endocuff clearly outperformed

Table II. Subgroup and sensitivity analysis of the adenoma detection rate. Subgroup analysis was restricted to a) right-sided adenomas and b) diminutive $(<5 \mathrm{~mm})$ adenomas. Sensitivity analysis was restricted to a) high quality studies, b) Endocuff Vision studies. Numbers in parentheses indicate $95 \%$ confidence intervals

\begin{tabular}{|c|c|c|c|c|c|}
\hline Subgroup & $\begin{array}{l}\text { No. of } \\
\text { Studies }\end{array}$ & $\begin{array}{c}\text { No. of } \\
\text { patients }\end{array}$ & $\mathrm{ADR}$ & Risk ratio $(95 \% \mathrm{CI})$ & $\begin{array}{l}\text { Within-group } \\
\text { heterogeneity }\left(\mathrm{I}^{2}\right)\end{array}$ \\
\hline Right-sided & 2 & 238 & $\begin{array}{l}\text { Endocuff: } 45.7 \%(36.8-54.7 \%) \\
\text { Cap: } 24 \%(17-45.1 \%)\end{array}$ & $2.04(0.93-4.49)$ & $45 \%$ \\
\hline Diminutive & 2 & 241 & $\begin{array}{l}\text { Endocuff: } 44.9 \%(35.9-53.8 \%) \\
\text { Cap: } 24.6 \%(17.4-44.5 \%)\end{array}$ & $2.74(1.53-4.90)$ & $15 \%$ \\
\hline High quality & 4 & 722 & $\begin{array}{l}\text { Endocuff: } 51 \%(47.4-54.7 \%) \\
\text { Cap: } 43.1 \%(31.8-54.3 \%)\end{array}$ & $1.18(0.92-1.51)$ & $35 \%$ \\
\hline Endocuff Vision & 2 & 419 & $\begin{array}{l}\text { Endocuff: } 50.8 \%(46.1-55.5 \%) \\
\text { Cap: } 38.5 \%(14-52.9 \%)\end{array}$ & $1.39(0.68-2.83)$ & $90 \%$ \\
\hline
\end{tabular}




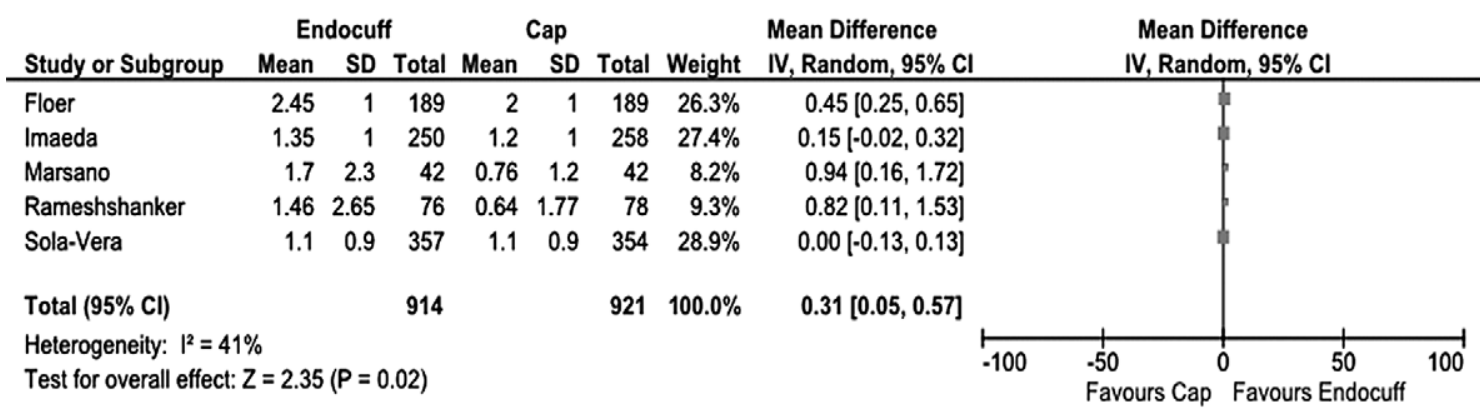

Fig. 3. Forrest Plot comparing endocuff-assisted and cap -assisted colonoscopy for mean adenoma per colonoscopy. Mean adenoma per colonoscopy was 1.61 (95\% CI 1.01-2.2) with endocuff and 1.16 (95\% CI 0.75-1.57) with cap. Mean difference was significantly in favour of endocuff-assisted colonoscopy $(0.31,95 \%$ CI $0.05-0.57)$.

the cap in terms of mean adenoma per colonoscopy (mean difference 0.31$)$ and diminutive $(\leq 5 \mathrm{~mm}$ ) adenomas. This finding supports the evidence of a higher detection with endocuff for smaller lesions, which are more likely to be missed in particular by non-expert endoscopists, and a greater overall number of polyps diagnosed as compared to capassisted colonoscopy. This aspect suggests a higher anticipated magnitude of benefit particularly for low-performing endoscopists (lower baseline ADR), as suggested by recent retrospective reports [25], whereas the improvement might be only marginal in expert operators. Third, the procedural characteristics do not seem to be influenced by the use of a specific add-on device over the other as both cecal intubation rate and insertion time were comparable in the two groups. Fourth, as already found in previous meta-analyses [9, 24], the use of distal attachment devices is safe with no incidence of serious adverse events.

Since there is a well-known association between ADR and risk of interval CRC, quantified by Corley et al. [6] as a $3 \%$ decrease in the risk of CRC with each $1 \%$ increase in ADR, we had already postulated in a previous network meta-analysis that all currently available methods to increase ADR, including add-on devices, may have a modest effect on decreasing rates of interval CRCs $[9,12]$. However, the interesting performance of endocuff could not be properly assessed and confirmed in previous reviews given the limited number of head-to-head RCTs directly comparing the add-on devices.

With this updated meta-analysis, we may confirm the favorable diagnostic performance of endocuff, more likely to be enhanced in low-performing endoscopists due to the higher detection of smaller adenomas and the greater overall number of polyps diagnosed. On the other hand, we may postulate that endocuff may lead to a modest benefit over cap on increasing ADR and decreasing rates of interval CRCs in endoscopists with high baseline ADR. The non-superiority of endocuff over cap in terms of higher overall ADR might be due to the limited number of available RCTs and their relative small sample size; further larger trials would be likely to help to evaluate and further contextualize the role of endocuff in quality endoscopy.

There are certain limitations to our study which merit further discussion. First, the number of included trials was low, and all of the included studies were unblinded RCTs, prone to performance and detection bias. However, this bias is not avoidable in endoscopy studies as the operator cannot be blinded to the device used. Second, some comparisons were impaired by the evidence of moderate heterogeneity, probably due to differences in participants and trial design. However, multiple sensitivity analyses were performed observing a consistent decrease in heterogeneity in several subsets, thus confirming the robustness of our results and excluding overt sources of heterogeneity that might have undermined the reliability of our findings. Another limitation is represented by the heterogeneous indications to colonoscopy in the included RCTs, whereas only trials conducted in the context of screening campaigns could provide reliable and robust data on the real efficacy of these devices in improving ADR. Finally, the included RCTs did not report data on the cost of the devices adopted and cost-effectiveness analysis was beyond the scope of our study.

Table III. Summary of findings reporting the comparative efficacy of endocuff-assisted and cap-assisted colonoscopy for improving sessile serrated adenoma detection rate, cecal intubation time and cecal intubation rate.

\begin{tabular}{|c|c|c|c|c|c|}
\hline Outcome & $\begin{array}{l}\text { No. of } \\
\text { Studies }\end{array}$ & $\begin{array}{l}\text { No. of } \\
\text { patients }\end{array}$ & Pooled Estimate & Risk ratio (95\% CI) & $\begin{array}{l}\text { Within-group } \\
\text { heterogeneity (I2) }\end{array}$ \\
\hline $\begin{array}{l}\text { Sessile Serrated adenoma } \\
\text { detection rate }\end{array}$ & 3 & 746 & $\begin{array}{l}\text { Endocuff: } 9.6 \%(0-19 \%) \\
\text { Cap: } 6.8 \%(0-15 \%)\end{array}$ & $1.36(0.72-2.59)$ & $0 \%$ \\
\hline Cecal Intubation Rate & 4 & 722 & $\begin{array}{l}\text { Endocuff: } 97.6 \%(95.5-99.6 \%) \\
\text { Cap: } 98.7 \%(97.4-100 \%)\end{array}$ & $0.99(0.98-1.00)$ & $19 \%$ \\
\hline Outcome & $\begin{array}{l}\text { No. of } \\
\text { Studies }\end{array}$ & $\begin{array}{l}\text { No. of } \\
\text { patients }\end{array}$ & Pooled Estimate & $\begin{array}{l}\text { Mean Difference } \\
\qquad(95 \% \mathrm{CI})\end{array}$ & $\begin{array}{l}\text { Within-group } \\
\text { heterogeneity (I2) }\end{array}$ \\
\hline Cecal Intubation Time & 4 & 1457 & $\begin{array}{l}\text { Endocuff: } 6.87 \text { (3.95-9.78) } \\
\text { Cap: } 6.87(3.91-9.83)\end{array}$ & $0.13(-0.47$ to 0.73$)$ & $32 \%$ \\
\hline
\end{tabular}




\section{CONCLUSIONS}

Endocuff seems to provide higher adenoma detection rates as compared to cap, in particular concerning smaller polyps. Further RCTs are warranted in order to confirm this favorable trend and to implement the endocuff use in the clinical practice.

\section{Conflicts of interest: None to declare.}

Authors' contribution: A.F. conceived and designed the study, analyzed the data. A.F. and R.V.B. drafted the manuscript. R.S. revised the final manuscript. All of the authors approved the final version of the manuscript.

Acknowledgements: We thank Miss Elektra Fike-Data for her help in reviewing and revising the manuscript for grammar and syntax.

Supplementary material: To access the supplementary material visit the online version of the J Gastrointestin Liver Dis at http://dx.doi. org/10.15403/jgld-1239

\section{REFERENCES}

1. Siegel R, Desantis C, Jemal A. Colorectal cancer statistics, 2014. CA Cancer J Clin 2014;64:104-117. doi:10.3322/caac.21220

2. Winawer SJ, Zauber AG, Ho MN, et al. Prevention of colorectal cancer by colonoscopic polypectomy. The National Polyp Study Workgroup. N Engl J Med 1993;329:1977-1981. doi:10.1056/NEJM199312303292701

3. Zauber AG, Winawer SJ, O’Brien MJ, et al. Colonoscopic polypectomy and long-term prevention of colorectal-cancer deaths. N Engl J Med 2012;366:687-696. doi:10.1056/NEJMoa1100370

4. Kaminski MF, Thomas-Gibson S, Bugajski M, et al. Performance measures for lower gastrointestinal endoscopy: a European Society of Gastrointestinal Endoscopy (ESGE) Quality Improvement Initiative. Endoscopy 2017;49:378-397. doi:10.1055/s-0043-103411

5. Kaminski MF, Regula J, Kraszewska E, et al. Quality indicators for colonoscopy and the risk of interval cancer. N Engl J Med 2010;362:1795-1803. doi:10.1056/NEJMoa0907667

6. Corley DA, Jensen CD, Marks AR, et al. Adenoma detection rate and risk of colorectal cancer and death. N Engl J Med 2014;370:1298-1306. doi:10.1056/NEJMoa1309086

7. Spadaccini M, Frazzoni L, Vanella G, et al. Efficacy and Tolerability of High- vs Low-Volume Split-Dose Bowel Cleansing Regimens for Colonoscopy: A Systematic Review and Meta-analysis. Clin Gastroenterol Hepatol 2020;18:1454-1465.e14. doi:10.1016/j. cgh.2019.10.044

8. Barclay RL, Vicari JJ, Doughty AS, Johanson JF, Greenlaw RL. Colonoscopic withdrawal times and adenoma detection during screening colonoscopy. N Engl J Med 2006;355:2533-2541. doi:10.1056/ NEJMoa055498

9. Facciorusso A, Triantafyllou K, Murad MH, et al. Compared Abilities of Endoscopic Techniques to Increase Colon Adenoma Detection Rates: A Network Meta-analysis. Clin Gastroenterol Hepatol 2019;17:2439-2454 e25. doi:10.1016/j.cgh.2018.11.058
10. Rex DK, Repici A, Gross SA, et al. High-definition colonoscopy versus Endocuff versus EndoRings versus full-spectrum endoscopy for adenoma detection at colonoscopy: a multicenter randomized trial. Gastrointest Endosc 2018;88:335-344. doi:10.1016/j.gie.2018.02.043

11. Facciorusso A, Del Prete V, Buccino V, Valle ND, Nacchiero MC, Muscatiello N. Full-spectrum versus standard colonoscopy for improving polyp detection rate: A systematic review and meta-analysis. J Gastroenterol Hepatol 2018;33:340-346. doi:10.1111/jgh.13859

12. Facciorusso A, Del Prete V, Buccino RV, et al. Comparative Efficacy of Colonoscope Distal Attachment Devices in Increasing Rates of Adenoma Detection: A Network Meta-analysis. Clin Gastroenterol Hepatol 2018;16:1209-1219.e9. doi:10.1016/j.cgh.2017.11.007

13. Gkolfakis P, Tziatzios G, Facciorusso A, Muscatiello N, Triantafyllou $\mathrm{K}$. Meta-analysis indicates that add-on devices and new endoscopes reduce colonoscopy adenoma miss rate. Eur J Gastroenterol Hepatol 2018;30:1482-1490. doi:10.1097/MEG.0000000000001245

14. Higgins JP, Altman DG, Gotzsche PC, et al. The Cochrane Collaboration's tool for assessing risk of bias in randomized trials. BM] 2011;343:d5928. doi: 10.1136/bmj.d5928

15. DerSimonian R, Laird N. Meta-analysis in clinical trials. Control Clin Trials 1986;7:177-188. doi: 10.1016/0197-2456(86)90046-2

16. Imaeda $\mathrm{H}$, Yamaoka $\mathrm{M}$, Ohgo $\mathrm{H}$, et al. Randomized control trial of adenoma detection rate in Endocuff-assisted colonoscopy versus transparent hood-assisted colonoscopy. J Gastroenterol Hepatol 2019;34:1492-1496. doi:10.1111/jgh.14771

17. Floer M, Tschaikowski L, Krueger H, et al. Standard vs. endocuff vs. cap assistedcolonoscopy for polyp detection: arandomized controlled trial. Gastrointest Endosc 2018;87(6S):AB74. doi:10.1016/j.gie.2018.04.064

18. Marsano J, Johnson S, Yan S, et al. Comparison of colon adenoma detection rates using cap-assisted and Endocuff-assisted colonoscopy: a randomized controlled trial. Endosc Int Open 2019;7:E1585-E1591. doi:10.1055/a-0996-7891

19. Rameshshanker R, Tsiamoulos Z, Wilson A, et al. Endoscopic cuffassisted colonoscopy versus cap-assisted colonoscopy in adenoma detection: randomized tandem study-Detection in Tandem Endocuff Cap Trial (DETECT). Gastrointest Endosc 2020;91:894-904.e1. doi:10.1016/j.gie.2019.11.046

20. Sanchez Yague A, Garcia-Gavilan M, Alcalde-Vargas A, Sanchez-Cantos A. Comparison of high-definition colonoscopywithout cap, with regular cap or with endocuff: a multicenter prospective study. Gastrointest Endosc. 2019;89(6S):AB394. doi:10.1016/j.gie.2019.03.594

21. Sola-Vera J, Catalá L, Uceda F, et al. Cuff-assisted versus cap-assisted colonoscopy for adenoma detection: results of a randomized study. Endoscopy 2019;51:742-749. doi:10.1055/a-0901-7306

22. Rex DK, Schoenfeld PS, Cohen J, et al. Quality indicators for colonoscopy. Gastrointest Endosc 2015;81:31-53. doi:10.1016/j.gie.2014.07.058

23. Aziz $M$, Desai $M$, Hassan $S$, et al. Improving serrated adenoma detection rate in the colon by electronic chromoendoscopy and distal attachment: systematic review and meta-analysis. Gastrointest Endosc 2019;90:721-731.e1. doi:10.1016/j.gie.2019.06.041

24. Williet N, Tournier Q, Vernet C, et al. Effect of Endocuff-assisted colonoscopy on adenoma detection rate: meta-analysis of randomized controlled trials. Endoscopy 2018;50:846-860. doi:10.1055/a-0577-3500

25. Okagawa Y, Sumiyoshi T, Tomita Y, et al. Endocuff-Assisted versus Cap-Assisted Colonoscopy Performed by Trainees: A Retrospective Study. Clin Endosc 2020;53:339-345. doi:10.5946/ce.2019.124 